\title{
New Estimates of the Elasticity of Marginal Utility for the UK
}

\author{
Ben Groom ${ }^{1}$ (D) . David Maddison Pr. ${ }^{2}$
}

Accepted: 28 February 2018 / Published online: 30 March 2018

(C) The Author(s) 2018

\begin{abstract}
This paper provides novel empirical evidence on the value of the elasticity of marginal utility, $\eta$, for the United Kingdom. $\eta$ is a crucial component of the social discount rate (SDR), which determines the inter-temporal trade-offs that are acceptable to society. Using contemporaneous and historical data, new estimates are obtained using four revealedpreference techniques: the equal-sacrifice income tax approach, the Euler-equation approach, the Frisch additive-preferences approach and risk aversion in insurance markets. A metaanalysis indicates parameter homogeneity across approaches, and a central estimate of 1.5 for $\eta$. The confidence interval excludes unity, the value used in official guidance by the UK government. The term structure of the SDR is then estimated. The result is a short-run SDR of $4.5 \%$ declining to $4.2 \%$ in the very long-run. This is higher and flatter than the UK official guidance. The difference stems from incorrect calibration of social welfare and estimation of the diffusion of growth. Other things equal, the results suggest that current UK guidance might need to be updated.
\end{abstract}

Keywords Elasticity of marginal utility $\cdot$ Social rate of time preference $\cdot$ Social discount rate $\cdot$ Cost-Benefit analysis

JEL Classification D60 $\cdot \mathrm{D} 61 \cdot \mathrm{H} 24 \cdot \mathrm{R} 13$

Ben Groom

b.groom@1se.ac.uk

David Maddison Pr.

d.j.maddison@bham.ac.uk

1 Department of Geography and Environment, London School of Economics, Hougton Street, London WC2A 2AE, UK

2 Department of Economics, University of Birmingham, JG Smith Building, Birmingham B15 2TT, UK 


\section{Introduction}

Whether or not public investments and policy measures improve societal welfare is one of the most important questions confronting economists. The answer to this question requires a clear metric of inter-temporal social welfare, against which alternative investments and policies can be compared. The choice of social welfare function (SWF) determines a social discount rate (SDR), which reflects the rate at which society is willing to make inter-temporal trade-offs of consumption. Discounting the future is an essential step in social cost-benefit analysis (CBA) since it identifies which investments or policies have a rate of return sufficient to raise social welfare. CBA is central to the economic analysis of public interventions, so an important question is therefore: do governments really reflect societal preferences in their choice of the SDR (at least insofar as societal preferences are revealed by private decisions)? The empirical analysis in this paper suggests that the UK government might not.

The SDR determines the weight that is placed on future costs and benefits in CBA, summarising how the SWF accounts for well-being in the future. Increasingly these days, public policy has implications for the well-being of successive generations, not just the current one. Climate change mitigation, nuclear energy and the valuation of natural capital are all examples of such policies (Arrow et al. 2013a, b; Gollier 2012; NCC 2017; Fenichel et al. 2016). Whether or not, or how much to invest in intergenerational projects is extremely sensitive to the SDR. For this reason, determining the SDR has been described as "one of the most critical problems in all of economics" (Weitzman 2001).

This paper focusses on the way in which social welfare is measured by Her Majesty's Treasury in the UK, and the SDR that it uses in its guidelines on CBA: the "Green Book: Appraisal and Evaluation in Central Government" (HMT 2003). Every department in the UK Government is obliged to follow the guidelines in the Green Book in evaluating public projects, and so it has considerable influence. The SDR that HM Treasury uses is a risk-free Social Rate of Time Preference (SRTP) calibrated according to the Ramsey Rule: SRT P = $\delta+\eta g$. The SRTP reflects the typical discounted utilitarian inter-temporal SWF in which the instantaneous utilities of a representative agent are discounted at a rate $\delta$, the elasticity of marginal utility is $\eta$ and per capita growth rate of consumption is $g$. Two critical features of the Green Book guidelines on the SDR are analysed in this paper.

Our primary focus is on the elasticity of marginal utility, $\eta$, which is a key determinant of the SDR. $\eta$ reflects the responsiveness of the representative agent's marginal utility to changes in consumption, and determines the "wealth effect" $(\eta g)$ in the SDR. Given the sensitivity of project appraisal to the SDR it is surprising to find that the estimation of $\eta$ has not received much serious attention. Furthermore, the attention it has received has led to considerable disagreement on the matter, sometimes creating more heat than light (Stern 2007; Dasgupta 2008; Nordhaus 2007).

One source of disagreement on this matter concerns the appropriate source of information with which to calibrate the SWF: subjective normative/prescriptive views or positive/descriptive data (Arrow et al. 1996; Dasgupta 2008). The analysis in this paper takes the view, widely held amongst CBA practitioners, that the SWF should reflect the preferences observed in society. Within the Ramsey framework $\eta$ can be interpreted as reflecting a societal preference for consumption smoothing, inequality aversion or risk aversion. Implicit to the Ramsey approach is that $\eta$ ought not to depend on the domain (inequality, inter-temporal substitution, substitution between goods, and risk aversion) in which the agent is making decisions. That is, aversion to differences in consumption is the same regardless of whether it occurs between individuals today, across time or across risky scenarios. Using revealed 
preference methodologies in each of these domains we provide new estimates of the elasticity of marginal utility for the UK. This allows us to empirically test the theoretical proposition of parameter homogeneity across domains. ${ }^{1}$ Although our focus is mainly on revealed preference methodologies this is certainly not to say that we think stated preference approaches are incapable of providing credible estimates of $\eta$. One important feature of the studies that we present however is the fact that they all use secondary data.

The second focus of the paper is on the term structure of the SDR. The Green Book recommends a declining term structure of discount rates for costs and benefits with longer maturities. This guidance is also routinely followed in public policy appraisal. ${ }^{2}$ The precise shape of the term structure depends on the nature of the SWF, but also on the level of persistence in the diffusion of the growth of consumption. The current Green Book term structure is not based on a thorough empirical analysis of the time series properties of UK growth (see Groom and Hepburn 2017). In order to provide a more robust basis for the guidelines on long-term CBA, we estimate an empirical term structure of discount rates for the UK, by estimating the growth diffusion process in the UK and calibrating using our estimates of $\eta$.

The results of our analysis provide grounds for believing that the Green Book guidelines might need to be updated on two counts. First, a meta-analysis of the four new estimates of $\eta$ plus another recently-provided estimate indicates that they are not significantly different from each other, yet significantly different from unity. That is, the hypothesis that $\eta=1$, the value used to calibrate the SWF and SDR in the Green Book, is rejected. In short, HM Treasury is not valuing social welfare in accordance with the preferences revealed by UK citizens, no matter in which domain these preferences are revealed. Second, neither does the Green Book term structure of the SDR reflect societal preferences for the distant future, given how growth is expected to diffuse. The estimated impact of persistence on the term structure of SDRs does not provide justification for the current SDR being as low as $1 \%$ for horizons of 300 years. The term structure should decline to around $2.5-3 \%$ at most.

The analysis in this paper is timely since in March 2018 HM Treasury published its conclusions following what was colloquially referred to as the "refresh" of the Green Book guidelines. Our results suggest that the way in which HM Treasury evaluates social welfare in both the short- and the long-run should probably also be refreshed. Yet the influence of this recommendation goes further than this. It has recently been recommended that discounting procedures used by the Office for National Statistics in the calculation of the UK National Accounts should be harmonised with the Green Book. ${ }^{3}$ Our recommendations could influence the estimation of the National Accounts, including those for human and natural capital. ${ }^{4}$ Further afield, the US National Academy of Sciences recently released guidance on the estimation of the Social Cost of Carbon (SCC) (NAS 2017). Its lengthy chapter on social

\footnotetext{
1 A referee suggests that the implications may be more far-ranging in that it serves as a test of whether a uniform value of eta in the public domain is warranted as opposed to more complex approaches such as Epstein-Zin preferences (Epstein and Zin 1989).

2 For instance the recent appraisal of the high speed rail link from London to Birmingham (HS2) used the declining term structure of discount rates:

https://www.gov.uk/government/uploads/system/uploads/attachment_data/file/365065/S_A_1_Economic_c ase_0.pdf, page 24. The Department of Environmental Food and Rural Affairs (DEFRA) also uses this term structure in its ecosystem service valuation tool: http://sciencesearch.defra.gov.uk/Document.aspx?Docume $\mathrm{nt}=13698$ 13667_EnvironmentalValueLook-Up(EVL)Tool_eftec_October2015_v4.xlsm.

3 See: https://www.ons.gov.uk/file?uri=/economy/nationalaccounts/uksectoraccounts/methodologies/natural capital/discountingforenvironmentalaccounts.pdf.

4 Accounting for changes in the stocks of natural capital in the National Accounts is an initiative of the Natural Capital Committee that reports to the Chancellor of the Exchequer. See (NCC 2017) for details.
} 
discounting concludes that Ramsey discounting is a desirable approach to the evaluation of the SCC, and emphasises the need for robust methodologies for the estimation of its parameters. Recent debate suggests that revealed preference estimates of such parameters are more acceptable in the US (Drupp et al. 2018). So the methods and procedures we use might provide guidance for future work in the US and elsewhere. ${ }^{5}$ Finally, while our focus has been on the importance of estimating the elasticity of marginal utility for CBA, the results of this paper are also relevant to the evaluation of non-marginal interventions, such as Integrated Assessment Modelling of climate change mitigation and macro-economic policy simulations. Such analyses require a direct calibration of a social welfare function. ${ }^{6}$ Our results therefore provide a revealed preference benchmark for a broader range of policy evaluations, beyond the confines of CBA.

The paper proceeds as follows. We first provide some background on social discounting and the Ramsey Rule. We then utilize five revealed preference methodologies to estimate $\eta$ : the equal-sacrifice approach, the Euler-equation approach, the Frisch additive-preferences approach, an approach based on insurance and the subjective-wellbeing approach. ${ }^{7}$ We estimate the first four of these methodologies improving on previous empirical work in several important ways. First, for the equal-sacrifice income tax approach we obtain a representative estimate of $\eta$ by appropriately weighting by the number of income tax payers in each tax bracket. Second, we analyse unique historical data on income tax schedules stretching back to 1948 and address a number of technical issues thrown up by earlier research. Third, we estimate the Euler equation using data from 1970 to 2011 checking carefully for the existence of parameter stability and endogeneity. Fourth, in undertaking the Frisch additive-preferences approach, we test the underlying assumption of additive preferences, something ignored by previous research.

A meta-analysis of the estimates is then undertaken to obtain a single 'best' estimate and test our hypotheses concerning the homogeneity and value of $\eta$. Finally, we estimate a growth diffusion process for the UK and calibrate the term structure of the SDR using our estimate of $\eta$. Taken together, our empirical evidence shows that HM Treasury's calibration of social welfare arguably does not adequately represent society's revealed preferences for the shortand the long-run.

\section{The Ramsey Rule and Its Calibration}

The workhorse specification of inter-temporal welfare is the discounted Utilitarian framework, which leads to the following expression for the SDR of the following form, known as the Ramsey Rule:

$$
r=\delta+\eta g
$$

\footnotetext{
5 A similar discussion of the social discount rate appears in a report from January 2017 by the Council of Economic Advisers: see https://obamawhitehouse.archives.gov/sites/default/files/page/files/201701_cea_dis counting_issue_brief.pdf.

6 Integrated Assessment Models like William Nordhaus' DICE model undertake full welfare analysis, requiring a direct calibration of the social welfare function. The Bank of England undertakes simulations of monetary and fiscal policy in dynamic stochastic general equilibrium models. The outcomes are highly sensitive to estimates of parameters such as the elasticity of marginal utility (e.g. Nordhaus 2014; Kaplan et al. 2016; Burgess et al. 2013).

7 Space does not allow a review the stated preference approach to estimating $\eta$ by means of controlled experiments examining aversion to inequality or risk aversion. Neither do we estimate $\delta$ or undertake a review of the extensive literature on its normative and positive arguments (e.g. Arrow 1999; Frederickson et al. 2002).
} 
where $r$ is the social rate of return to capital, $\delta$ is the pure rate of time preference, $g$ is the average per capita consumption growth rate and $\eta$ is the elasticity of marginal utility.

Equation (1) is known as the Ramsey rule, after Ramsey (1928). The right hand side of (1) is commonly referred to as the SRTP, and is argued to be the appropriate risk-free SDR for the appraisal of public projects (Lind 1982; Feldstein 1964). The UK, France, and many other countries use the SRTP as the SDR in public project appraisal (e.g. HMT 2003; Lebegue 2005; ADB 2007; MNOF 2012; Quinet 2013). Beyond this, the International Panel on Climate Change (IPCC) fifth assessment report by Working Group III, centre their discussion of inter-generational equity on this model (Kolstad et al. 2014, pp. 229-231), while the same representative agent approach is used in most Integrated Assessment Models of climate change (Nordhaus 2014). The value of the Ramsey Rule is also recognised in the recent National Academy of sciences report of the Social Cost of Carbon (NAS 2017). Views differ as to the correct value of the parameters of the Ramsey Rule: $\delta, \eta$ and $g$. The Green Book uses values of 1.5, 1 and 2 respectively for a short-term risk-free SDR of $3.5 \%$ (HMT 2003). ${ }^{8}$ The French government was advised to use values equivalent to 0,2 and 2 respectively (Lebegue 2005). More recent recommendations propose a risk free SDR of $2.5 \%$ (Quinet 2013). Disagreement on the correct value of $\delta$ has rumbled on since Ramsey (1928) whilst, albeit for quite different reasons, opinions also differ sharply on the correct value of $\eta{ }^{9}$

Disagreement over the value of $\eta$ arises because it has several different interpretations in the Ramsey context: intra-temporal inequality aversion, inter-temporal inequality aversion or risk aversion. These interpretations of $\eta$ give rise to separate methods of estimation which have historically yielded different estimates. This is the main source of disagreement among economists (Dasgupta 2008; Drupp et al. 2018). For instance, Atkinson et al. (2009) suggest that the concepts are "siblings, not triplets", meaning related, but not numerically identical. It has also been observed that disentangling the concepts helps resolve the so-called riskfree and equity premium puzzles (Weil 1989). Last, mainly for intergenerational projects, economists also disagree on whether a positive or a normative perspective should be adopted to the estimation of the parameters of the SRTP, including $\eta .{ }^{10}$

The critical role of $\eta$ on the risk-free discount rate can also be illustrated when uncertainty in growth $(g)$ is considered and the Ramsey rule must be extended. In the simplest case in which $\mathrm{g}$ is i.i.d. normal with mean $\mu$ and variance $\sigma^{2}$, the Ramsey rule becomes ${ }^{11}$ :

$$
S R T P=\delta+\eta \bar{g}-0.5 \eta(\eta+1) \sigma^{2}
$$

where $\bar{g}$ is the expected value of the annual consumption growth rate (Gollier 2012). ${ }^{12}$ The final term on the right hand side of this equation is known as the 'prudence' effect, and reflects a precautionary motive for saving. If $\eta>0$ this obviously reduces the risk-free SRTP and the size of this correction is determined by $\eta$.

For long-term CBA, there is now much interest in policy circles about the term structure of the SDR. Many theoretical arguments have been presented for a term structure which

\footnotetext{
8 An exception was made for forestry which remains entitled to use a discount rate of $3 \%$.

9 The impartial consequentialist tradition famously takes the normative view that all generations should be equal treated equally with regard to their utility i.e. that $\delta=0$. Axiomatic treatments such as Koopmans (1960) and agent relative ethics (e.g. Arrow 1999) suggest $\delta>0$, typically without specifying a number.

10 This lay at the heart of the debate following the Stern Review e.g. Dasgupta (2008), Nordhaus (2007) and Stern (2007).

11 That is: $c_{t}=c_{0} \exp (x t)$, where $x \sim N\left(\mu, \sigma_{c}^{2}\right)$.

12 When $x$ is lognormal the growth rate of expected consumption is given by: $\bar{g}=E \exp (\tilde{x})=\mu+0.5 \sigma^{2}$.
} 
declines with the time horizon. ${ }^{13}$ Most of these require uncertainty and persistence in either $\mathrm{g}$ or $\mathrm{r}$ itself. For instance, if $\mathrm{g}$ is subject to autocorrelation, this can provide a justification for declining discount rates. In the simple case where $g$ follows a mean reverting process it is straightforward to show that the short-run and long-run risk-free SRTP become respectively (Gollier 2012, ch 3): ${ }^{14}$

$$
r_{t}= \begin{cases}\rho+\eta \mu-0.5 \eta^{2}\left[\sigma_{x}^{2}+\sigma_{y}^{2}\right] & \text { for } t=1 \\ \rho+\eta \mu-0.5 \eta^{2}\left[\sigma_{x}^{2}+\frac{\sigma_{y}^{2}}{(1-\phi)^{2}}\right] & \text { for } t=\infty\end{cases}
$$

where $\phi$ measures the degree of persistence in $g$. In this context, the value of $\eta$ has additional significance; other things equal, it determines the shape of the term structure of risk-free discount rates in the intervening period and the extent of its decline with the time horizon. ${ }^{15}$

A wide range of estimates for $\eta$ exists in the literature. Based on a variety of methodologies such as the equal-sacrifice income tax approach (see below) and estimates of the Eulerequation, Stern (1977) advocates a value of around 2 with a possible range of 1 to 10. Based on a review of the revealed preference literature, Pearce and Ulph (1995) suggest a value of between 0.7 and 1.5, and a best-guess estimate of 0.83 based on the estimates from the Euler-equation provided by Blundell et al. (1994). Cowell and Gardiner (1999) point to a range of 0.5-4.0 based on similar range of methodologies whilst Evans and Sezer (2005) apply the equal-sacrifice income tax approach to all the countries of the European Union and find that values fall between 1.3 and 1.6. More recently, in response to the Stern Review, Gollier (2006) suggested a value between 2 and 4 based on a thought experiment based on willingness to pay to reduce risk, while Dasgupta (2008) prefers a value of 2 on the basis of introspection on inequality aversion. Drupp et al. (2018) obtain a more representative picture of expert opinion on the matter in their survey over 200 discounting experts, for whom the mean (median) of values of $\eta$ was 1.3 (1).

The range of these estimates is wide partly as a result of the diverse methodologies employed and the subjective manner in which they are combined. Also, with few notable exceptions, the applications have been empirically weak and tests of the theoretical assumptions underpinning these methodologies are absent. Indeed, the influential article by Stern concludes in one section "it is hoped that enough has been said to prevent any reader taking

\footnotetext{
13 Recent literature on discounting argues that the term structure of discount rates should decline with the time horizon considered e.g. Arrow et al. (2013a, b). Declining discount rates are also encountered in the Green Book (HMT, 2003). The French and Norwegian governments use a declining term structure for risk free projects (Lebegue 2005; MNOF 2012) whilst the US government has been influenced strongly by the theoretical literature on declining discount rates (IAWG 2010; USEPA 2010).

14 Where consumption evolves according to the following system:

$c_{t+1}=c_{t} \exp \left(x_{t}\right)$

$x_{t}=\mu+y_{t}+\varepsilon_{x t}$

$y_{t}=\phi y_{t-1}+\varepsilon y t$

The error terms are assumed to be mean zero and i.i.d. normal (Gollier 2012). The term structure of the SRTP is then given by:

$S R T P=\delta+\eta \bar{g}-0.5 \eta^{2}\left[\sigma_{x}^{2}+\frac{\sigma_{y}^{2}}{(1-\varphi)^{2}}\right]+\left[\eta y_{-1} \varphi \frac{1-\varphi^{t}}{t(1-\varphi)}-0.5 \eta^{2} \frac{\sigma_{y}^{2}}{(1-\varphi)^{2}}\left(\frac{\varphi^{2 t}-1}{\left(\varphi^{2}-1\right)}-2 \varphi \frac{\varphi^{t}-1}{t(\varphi-1)}\right)\right]$

where $y$ is an observed state space variable. Equation (6) assumes $y_{-1}=0$, hence growth is at trend. There are strong arguments to adjust the SDR when off trend. This would lead to low and increasing discount rates in recession, and high and declining ones in the boom times (Gollier 2012, Ch4).

15 Systematic risk could be incorporated using the consumption CAPM approach which would add a risk premium equal to $\beta \eta \sigma^{2}$ to the discount rate, where $\sigma^{2}$ is the volatility of growth and $\beta$ is the project specific "beta". The Green Book does not deal with project risk in this way.
} 
such numbers away for direct use in cost-benefit analysis" (Stern 1977, p. 244). Given the sensitivity of CBA to the SDR, it is obviously important to have precise estimates of $\eta$. The rest of the paper provides more robust estimates that we hope will be used in CBA.

\section{Estimating $\eta$ from Income Tax Schedules: The Equal-Sacrifice Approach}

In this section we use 'socially-revealed' preferences to infer the value of $\eta$. More specifically, we analyse information on the progressivity of income tax schedule to infer the value of $\eta$ under the assumption of equal sacrifice. This approach also requires that the utility function takes a known (almost invariably iso-elastic) form. The justification for the assumption of equal-sacrifice may be traced back to Mill (1848) who stated: "Equality of taxation, as a maxim of politics, means equality of sacrifice". In this exercise $\eta$ can also be interpreted as a measure of society's aversion to inequality.

Algebraically, the principle of equal-sacrifice implies that for all income levels $\mathrm{Y}$ the following equation must hold:

$$
U(Y)-U(Y-T(Y))=k
$$

where $k$ is a constant, $Y$ is gross income, $U$ is utility and $T(Y)$ is the total tax liability according to the income tax schedule. Assuming an iso-elastic utility function then differentiating this expression with respect to $Y$ and solving for $\eta$ yields (see e.g. Evans 2004a):

$$
\eta=\frac{\ln (1-M T R)}{\ln (1-A T R)}
$$

where $T(Y) / Y$ is the average tax rate (ATR) and $\partial T(Y) / \partial Y$ is the marginal tax rate (MTR).

Cowell and Gardiner (1999) argue that there is good reason to take seriously estimates derived from tax schedules: decisions on taxation have to be defended before an electorate and the values implicit in them ought, therefore, to be applicable in other areas where distributional considerations are important such as discounting or the determination of welfare weights. Such estimates have a particular appeal if one is concerned about a possible difference between societal preferences and individual preferences. At the same time however, there are concerns about whether a progressive income tax structure consistent with equal sacrifice would adversely impact work incentives (Spackman 2004). Furthermore, tests of the equality of sacrifice assumption are themselves impossible since they are necessarily based on a particular utility function. ${ }^{16}$

Previous studies have used income tax schedules to estimate $\eta$ in many different countries as well as at different income levels. ${ }^{17}$ Our focus however, is on evidence for the UK where empirical estimates are available from Stern (1977), Cowell and Gardiner (1999), Evans and Sezer (2005) and Evans (2008).

\footnotetext{
16 Strictly speaking equal sacrifice combined with a smooth utility function would imply a MTR that continually varies. For this reason alone an income tax structure characterised by a limited number of tax thresholds cannot fit perfectly the equal sacrifice model. Concerns also arise when interpreting revealed preference measures of inequality aversion such as this as reflecting intergenerational inquality aversion (Gollier 2017).

17 Evans (2005) for instance, provides evidence for 20 OECD countries. One striking observation about these estimates is that similar to ours they all lie in the range $1-2$, with the smallest estimate for Ireland $(\eta=1)$ and the largest being for Austria $(\eta=1.79)$.
} 
We now provide updated estimates of $\eta$ using the equal-sacrifice approach. Data taken from Her Majesty's Revenue and Customs (HMRC) website consists of $i=134$ observations on all earnings liable to income taxation including: earnings arising from paid employment, self employment, pensions and miscellaneous benefits. These observations are drawn from the tax years 2000-2001 through to the tax year 2009-2010 excluding the tax year 2008-2009 for which no data are available. Each tax year includes between 13 and 17 earnings categories. Together, these span almost the entire earnings distribution, from earnings only slightly in excess of the tax allowance up to earnings of $£ 1,940,000$. Also included (and critical for our purposes) is the number of individuals in each earnings category.

For mean earnings in each earnings category we calculate the ATR and the MTR using the online tax calculator http://listentotaxman.com/. The tax calculator separately identifies income tax and employee National Insurance Contributions (NICs). As with most previous papers the data generated assumes a single individual with no dependents or special circumstances (e.g. registered blind or repaying a student loan). ${ }^{18}$

Despite the (in our view fundamental) need to weight the observations according to the number of individuals in each earnings category this appears to have been largely overlooked in the literature (although see Stern 1977). The 'importance' weights we will employ for this purpose refer to the number of individuals in each earnings category divided by the total number of individuals in the sample. ${ }^{19}$ Hence, although our sample contains different numbers of observations in different tax years, each tax year receives equal weight. In what follows we demonstrate that employing weighted and un-weighted data yields different estimates of $\eta$. But only weighted data yields an estimate of $\eta$ which is representative of the population of income tax payers.

We also address the issue of whether or not to include NICs. Evans (2005) argues against their inclusion on grounds that: "An income tax-only model seems more in keeping with the underlying theory concerning equal absolute sacrifice". By contrast, Reed and Dixon (2005) find that there is no operational difference between them arguing that NICs are: "increasingly cast as a surrogate income tax". These views are echoed by Adam and Loutzenhiser (2007) who survey the literature concerned with combining NICs and income tax. They assert that: "NICs and national insurance expenditure proceed on essentially independent paths". Our view is that, whilst historically NICs embodied a contributory principle, this linkage has now all but disappeared, the key exception from this being the entitlement to a full state pension. ${ }^{20}$ Nevertheless, in what follows we examine the sensitivity of estimates of $\boldsymbol{\eta}$ to omitting NICs from the calculations.

Table 1 contains regression estimates for $\eta$ obtained from regressing $\ln \left(1-\mathrm{MTR}_{\mathrm{i}}\right)$ against $\ln \left(1-\mathrm{ATR}_{\mathrm{i}}\right)$ with the constant term suppressed. OLS Estimates from two models are reported. Model 1 is based on the un-weighted data and Model 2 is based on the weighted data. As discussed, the weights refer to the proportion of individuals contained in each particular income category in any given year. The un-weighted and weighted regression results are very different emphasising the importance of weighting the data to ensure that it is representative of the underlying population. But irrespective of whether the regression is weighted, if the

18 This is in contrast to Stern (1977) who considered a family with two children and a medium-sized mortgage. Since then the tax system has been radically restructured such that there are no longer any tax allowances for married couples (except those over the age of 75). Mortgage Interest Relief at Source (MIRAS) was abolished in April 2000.

19 Stern (1977) also advises that the data should be weighted according to the number of income tax payers within each income category.

20 Individuals are required to have 30 qualifying years, counted as years spent paying NICs, caring for someone for over 20 hours per week, getting child benefit, unemployed but actively seeking work or in full time training. 
Table 1 Constant $\eta$ OLS regression estimates

Note that the constant term has been suppressed. T-statistics in parentheses are robust

Table 2 Constant $\eta$ OLS regression estimates excluding NICs

Note that the constant term has been suppressed. T-statistics in parentheses are robust

\begin{tabular}{lll}
\hline $\begin{array}{l}\text { Dependent variable } \\
\ln \left(1-\mathrm{MTR}_{\mathrm{i}}\right)\end{array}$ & Model 1 & Model 2 \\
\hline $\ln \left(1-\mathrm{ATR}_{\mathrm{i}}\right)$ & 1.274 & 1.515 \\
& $(45.03)$ & $(32.22)$ \\
Weights & No & Yes \\
No. obs. & 134 & 134 \\
$\mathrm{R}^{2}$ & 0.8621 & 0.8867 \\
F statistic & $\mathrm{F}(1,133)=2027.59$ & $\mathrm{~F}(1,133)=1038.05$ \\
\hline
\end{tabular}

\begin{tabular}{lll}
\hline $\begin{array}{l}\text { Dependent variable } \\
\ln \left(1-\text { MTR }_{\mathrm{i}}\right)\end{array}$ & Model 3 & Model 4 \\
\hline $\ln \left(1-\right.$ ATR $\left._{\mathrm{i}}\right)$ & 1.300 & 1.627 \\
& $(38.87)$ & $(34.75)$ \\
Weights & No & Yes \\
No. obs. & 134 & 134 \\
R $^{2}$ & 0.9024 & 0.9053 \\
F Statistic & $\mathrm{F}(1,133)=1510.81$ & $\mathrm{~F}(1,133)=1207.43$ \\
\hline
\end{tabular}

constant elasticity and equal-sacrifice assumptions are correct, the hypothesis that $\eta$ is equal to unity can be rejected at the $1 \%$ level of confidence. For Model 2 which is the preferred model, the estimate of $\eta$ is 1.515 with a standard error of 0.047 . Table 2 presents two further OLS regression results this time excluding NICs. Once more there is a large difference between the results for the weighted (Model 3) and un-weighted (Model 4) regressions.

Whilst these calculations make use of recently published data on income tax liability at different points on the income distribution we can obviously go much further back in time if we instead confine ourselves to estimating $\eta$ for a person earning the average production wage (APW) and ignore other points on the income distribution.

This alternative historical analysis is arguably more relevant for long-term project appraisal. We use UK data drawn from the EuropTax database compiled by Lynch and Weingarten (2010). This database provides income tax schedules with options for evaluating the incidence of income tax on various types of household. For the purposes of this analysis however, we continue to consider a single person household. Note that NICs are also included in the analysis.

Figure 1 displays the MTR and ATR measured at the APW, along with the implied estimate of $\eta$. Over the period 1948-2007 this Figure shows that socially-revealed estimates of $\eta$, measured at the APW, declined significantly in the immediate aftermath of the WWII before stabilising at a lower level. This decline is caused by a narrowing of the gap between the MTR and ATR. The average value of $\eta$ over the entire time period is 1.45 with a $95 \%$ confidence interval of 1.38-1.51. It may also be appropriate to take into account the time series properties of the data, that the underlying persistence in political processes might introduce for instance (Cowell and Gardiner 1999), Modelled as a simple AR(1) process the series reverts to a mean of 1.57 with a $95 \%$ confidence interval of 1.09-2.07. The estimate of $\eta$ obtained using historical data is therefore statistically no different from the figure of 1.51 obtained earlier using more recent, more detailed data, despite its fluctuations over time. 


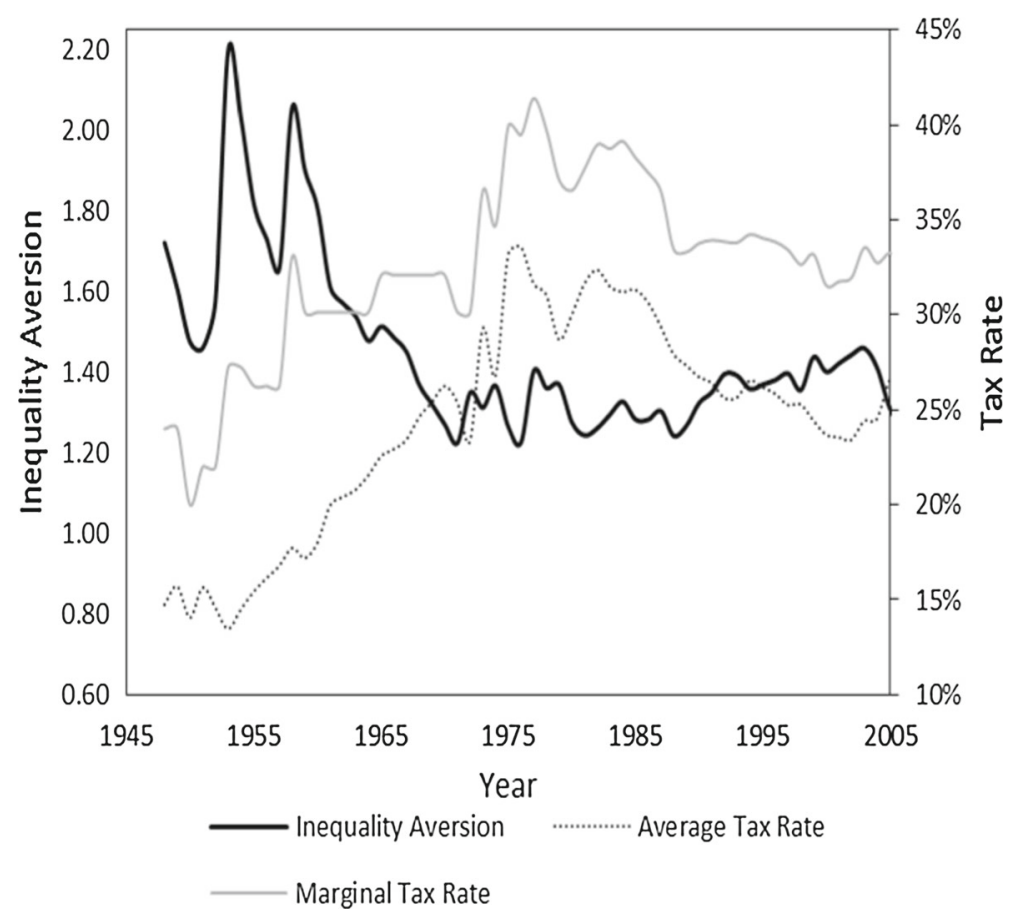

Fig. 1 MTRs and ATRs and the implied value of $\eta$ in the United Kingdom 1948-2005

\section{Life-Cycle Behavioural Models: The Euler-Equation Approach}

The preceding section sought to derive estimates of $\eta$ by observing societal choices. Estimates of $\eta$ however, can also be derived from individual households' observed saving decisions. More specifically, in the life-cycle model of household behaviour the household is viewed as allocating its consumption over different time periods in order to maximise a multiperiod discounted utility function subject to an intertemporal wealth constraint. Consumption decisions are affected by the rate of interest and households' attempts to smooth consumption over time according to (a) the extent that deferred consumption is less costly than immediate consumption and (b) the curvature of the utility function. To some e.g. Pearce and Ulph (1995), this is the preferred 'gold-standard' method of estimating $\eta$ since it avoids the untestable equal-sacrifice assumption and is thought to be conceptually closer to the dynamic context of social discounting than the equal-sacrifice approach, which relates to intra-generational inequality aversion.

In the life-cycle model, estimates of $\eta$ are derived from the so-called Euler-equation although in the macroeconomics literature this information is normally presented in terms of the elasticity of intertemporal substitution (EIS) which is equal to $1 / \eta$. At the household level, when the EIS is high households readily reallocate consumption in response to changes in the interest rate and are less concerned about consumption smoothing. In the context of the social discounting and the Ramsey formula, a high value of $\eta$ combined with a positive growth rate will lead to a higher social discount rate, other things equal. In this context $\eta$ measures inter-temporal inequality aversion. 
Using the Taylor series approximation, the solution to the canonical household problem of maximising discounted utility subject to a wealth constraint leads to the following empirical specification:

$$
\Delta \ln \left(C_{t}\right)=\alpha+\beta r_{t}+\varepsilon_{t}
$$

where $r_{t}$ is the real interest, the coefficient $\beta$ is the EIS, $\varepsilon$ is an error term and the intercept $\alpha$ yields information on the value of $\delta .^{21}$

The life-cycle model of household consumption behaviour rests on a large number of assumptions probably the most important of which is the presumed existence of perfect capital markets allowing households to borrow and lend in an unrestricted fashion. Estimates of the EIS may be impacted by periods of financial turbulence and prone to change following financial deregulation. And they may depend on the definition of consumption e.g. whether consumption includes the purchase of durable goods. And where analysts use aggregate rather than micro data this raises the question about how aggregate data accommodates changes in demographic composition and the changing 'needs' of households over the life-cycle. One might even question the convenient assumption that the intertemporal utility function is additively separable. For a recent meta-analysis of the empirical evidence on the EIS see Havranek (2015).

For the UK there appear to be 10 papers which provide estimates of the EIS. ${ }^{22}$ Each of these papers typically provides more than one estimate usually arising out of attempts to assess the sensitivity of results to changes in estimation technique, minor changes in the specification and different periods of time. These papers include Kugler (1988), Attanasio and Weber (1989), Campbell and Mankiw (1991), Patterson and Pesaran (1992), Robertson and Scott (1993), Attanasio and Weber (1993), Blundell et al. (1994), Van Dalen (1995), Attanasio and Browning (1995), Berloffa (1997) and Yogo (2004).

These studies differ considerably in terms of their sophistication and employ both microeconomic and macroeconomic data. Perhaps the most important feature of the literature however is the finding of statistically significant parameter instability. ${ }^{23}$ Such instability is unsurprising; the period 1970-1986 witnessed oil price shocks, record levels of inflation and an experiment with monetarism. Both the Building Societies Act and the Financial Services Act were passed by Parliament in 1986. It is hard to argue that these events will not have had some impact on intertemporal consumption allocation decisions.

We update the empirical evidence on the EIS for the UK. Data for the Euler-equation approach is taken from the Office for National Statistics (ONS) and the Bank of England (BOE) websites. Quarterly data is available from 1975Q1 through to 2011Q1. We employ data which has not been seasonally adjusted. Domestic spending in both current prices and 2006 prices is available for durable goods, semi-durable goods, non-durable goods and services. Following convention, we omit durable goods and form a price index $\mathrm{P}_{\mathrm{t}}$ for all other goods and

\footnotetext{
${ }^{21}$ Hansen and Singleton (1982) offer a more advanced treatment which allows the state equation governing the accumulation of wealth to contain an error term. This has the effect of adding an additional constant term which in turn has implications for the measurement of $\delta$. To be consistent with the bulk of the empirical literature we estimate the EIS rather than $\eta$.

22 These studies were identified using ECONLIT and searching for the terms "intertemporal elasticity of substitution" or "elasticity of intertemporal substitution" or "intertemporal substitution elasticity" combined with "United Kingdom" or "UK" anywhere in the text.

23 All studies but one use data prior to 1991 which was a period of marked financial deregulation in the United Kingdom.
} 
Table 3 OLS estimates of the Euler equation
Note that $* * *, * *$ and $*$ imply significance at the 1, 5 and $10 \%$ level respectively

\begin{tabular}{|c|c|c|}
\hline \multirow{2}{*}{$\begin{array}{l}\text { Dependent variable } \\
\Delta \operatorname{Ln}\left(C_{t}\right)\end{array}$} & Model 1 & Model 2 \\
\hline & $\begin{array}{l}\text { Coefficient } \\
\text { (T-statistic) }\end{array}$ & $\begin{array}{l}\text { Coefficient } \\
\text { (T-statistic) }\end{array}$ \\
\hline \multirow[t]{2}{*}{ Constant } & 0.043 & 0.043 \\
\hline & $(19.77)$ & (18.18) \\
\hline \multirow[t]{2}{*}{$r_{t}$} & 0.631 & 0.632 \\
\hline & $(9.35)$ & $(9.06)$ \\
\hline \multirow[t]{2}{*}{ DUMQ1 } & -0.134 & -0.134 \\
\hline & $(-35.22)$ & $(-34.54)$ \\
\hline \multirow[t]{2}{*}{ DUMQ2 } & -0.009 & -0.009 \\
\hline & $(-3.08)$ & $(-3.03)$ \\
\hline \multirow[t]{2}{*}{ DUMQ3 } & -0.025 & -0.025 \\
\hline & $(-7.62)$ & $(-7.45)$ \\
\hline \multirow[t]{2}{*}{ DUM1993Q2 } & & -0.000 \\
\hline & & $(-0.23)$ \\
\hline \multirow[t]{2}{*}{ DUM1993Q2 $\mathrm{x} \mathrm{r}_{\mathrm{t}}$} & & -0.026 \\
\hline & & $(-0.21)$ \\
\hline $\mathrm{R}^{2}$ & 0.9484 & 0.9485 \\
\hline F-statistic & $\mathrm{F}(4,140)=643.70 * * *$ & $\mathrm{~F}(6,138)=423.44 * * *$ \\
\hline Breusch-Pagan & $x^{2}(1)=1.06$ & $\chi^{2}(1)=0.91$ \\
\hline Durbin-Watson & 2.00 & 2.01 \\
\hline Reset & $\mathrm{F}(3,137)=2.52 *$ & $\mathrm{~F}(3,135)=2.88^{* *}$ \\
\hline
\end{tabular}

services using the share-weighted geometric mean of the price series for semi-durable goods, non-durable goods and services. Henceforth we refer to this as 'consumption'. Consumption is measured in constant 2006 prices. For the real interest rate $r_{t}$ we take the official Bank of England base rate minus the previously created price index. A quarterly series for population is created from mid-year population estimates using linear interpolation. ${ }^{24} \mathrm{C}$ is per capita consumption.

Table 3 displays an OLS regression of the per capita consumption growth rate $\Delta \operatorname{Ln}\left(C_{t}\right)$ against a constant term, $r_{t}$ and three dummy variables DUMQ1, DUMQ2 and DUMQ3 to account for seasonal effects. The regression displays no evidence of heteroscedasticity or autocorrelation and the test for functional form is significant only at the $10 \%$ level of confidence. In Model 2 we interact the real rate of interest with a dummy variable DUM1993Q2 which takes the value unity for observations from 1993Q2 onwards. The purpose of including this dummy variable which divides the sample in two is to conduct a Chow test for parameter stability. An F-test cannot reject the hypothesis of parameter stability i.e. that the dummy variable and the coefficient on the interacted term are both simultaneously zero with a $p$ value $=0.935 .{ }^{25}$ This is welcome but surprising in light of the problems encountered by earlier analyses. There is nevertheless now some ambiguity concerning the RESET test which is significant at the $5 \%$ but not at $1 \%$ level of confidence.

24 More specifically we use the data series EBAQ, UTIQ, UTIS, UTIK, UTIO, UTIA, UTIQ, UTII, UTIM from the ONS and IUQABEDR from the BOE.

25 The F-statistic is $\mathrm{F}(2,138)=0.07$. 
It is typical in the literature to address the endogeneity of the explanatory variables by using an instrumental variables approach. Table A.1 in the Appendix provides the results of this exercise where lagged values of the consumption growth rate, real interest rate and inflation rate are used as instruments. The results of this approach are essentially identical to the OLS results in Table 3, and test for endogeneity also point to the reliability of the OLS results. For this reason, all further analysis uses the results in Table 3.

To obtain an estimate of $\eta$ (the inverse of the coefficient on the real rate of interest, $\mathrm{r}_{\mathrm{t}}$ ) we use bootstrap techniques with 1000 replications. This procedure results in an estimate for $\eta$ of 1.584 with a $95 \%$ confidence interval of $1.181-1.987 .{ }^{26}$

\section{Additive Preferences and the Frisch Formula}

A third, and possibly the oldest technique for estimating $\eta$ moves away from the context of inequality aversion and focuses on the way in which marginal utility changes as a result of the consumption of particular goods. The Frisch formula relies on the presumed existence of additive preferences (elsewhere this property is referred to as 'strong separability' or 'wants independence'). ${ }^{27}$ Additivity implies that the extra utility obtained from consuming additional units of the additively separable commodity is independent of the quantity consumed of any other commodity. Given additivity all the information necessary for estimating $\eta$ can be obtained by analysing the demand for the additively separable commodity. In some developing country contexts this might be the only feasible means of estimating $\eta$.

For goods that enter the utility function in an additive fashion it can be shown that the following relationship holds (Frisch 1959):

$$
\eta=\frac{\kappa_{i}\left(1-w_{i} \kappa_{i}\right)}{\varepsilon_{i i}}
$$

where $\eta$ is as before, $w$ is the budget share, $\kappa$ is the income elasticity of demand and $\varepsilon$ is the own compensated elasticity of demand for good $i$. A derivation of this relationship is provided in the Appendix.

Evans (2008) provides a review of estimates of $\eta$ obtained using this technique. ${ }^{28}$ The studies therein are based on the demand for food, although a priori arguments for believing that food is additively separable are somewhat hard to find. Primary studies analyse the demand for food with the specific intention of estimating $\eta$. Secondary studies simply borrow estimates from existing studies of consumer demand e.g. Blundell et al. 1993; Banks et al. 1997. ${ }^{29}$ Either way, in order to invoke the Frisch formula it is has to be assumed that food is additively separable.

So far as the United Kingdom is concerned there seem to be three studies of the demand for food undertaken for the purposes of estimating: Evans and Sezer (2002), Evans (2004b) and Evans et al. (2005).

\footnotetext{
26 In their recent meta-analysis of available estimates of the EIS for different countries Havranek et al. (2014) present a best estimate for the UK of 0.487 with a standard error of 0.070 . This is not significantly different from our own estimate of 0.631 with a standard error of 0.067 .

27 In fact the Euler-equation approach also relies on the assumption of an additively separable utility function.

28 In the survey presented by Evans the only available evidence is in the form of point estimates.

29 Neither Blundell et al. (1993) nor Banks et al. (1997) test for the additive separability of food. Both these studies employ microeconomic data whereas all those studies undertaken specifically with a view to estimating the elasticity of marginal utility utilise aggregate data.
} 
The obvious limitation of all these studies is the absence of any simultaneous evidence suggesting that food is additively separable. ${ }^{30}$ But if food is not additively separable from other commodities then the Frisch formula does not apply. Furthermore, it is important to avoid attaching too much significance to the fact that resulting estimates appear to take 'plausible' values since, as Deaton and Muellbauer (1980) note, even with the failure of additivity, it is not surprising that estimates of $\eta$ should fall into the range $1-3$. This is because $\eta$ will always be estimated as approximately equal to the average ratio of uncompensated own price elasticities and income elasticities. And with the typical level of aggregation adopted in consumer demand studies, an estimate of 1-3 is entirely plausible.

The approach taken here is to analyse the demand for food using the Rotterdam demand system whilst explicitly testing the validity of the restrictions associated with the additivity assumption.

The Rotterdam demand system has long served as a vehicle for testing the theoretical postulates of consumer demand theory. Furthermore the Rotterdam system has been found comparable to the more modern AIDS system in terms of its ability to estimate the value of key parameters. For a recent discussion of the Rotterdam model and evidence of its enduring appeal presented in terms of the number of papers published using the Rotterdam demand system relative to other well-known demand systems see Clements and Gao (2015).

Of particular interest to us is the fact that the Rotterdam system may be used to test and impose the restrictions associated with additivity in a relatively straightforward manner. ${ }^{31}$ And once they have been imposed an estimate of $\eta$, which is modelled as a constant, is directly available along with its associated standard error. ${ }^{32}$

The Rotterdam system is defined by the equation:

$$
w_{i} d \ln \left(Q_{i}\right)=a_{i}+b_{i} d \ln (R)+\Sigma_{j} c_{i j} d \ln \left(P_{i j}\right)
$$

where

$$
d \ln (R)=d \ln (Y)-\Sigma_{i} w_{i} d \ln \left(P_{i}\right)
$$

and $w$ is the share, $Q$ is the quantity and $P$ is the price of commodity $i$. The variable $R$ can be interpreted as real income. Note the existence of an intercept allowing for autonomous changes in the demand for food. This system is then implemented using time series data with the following approximations:

$$
\begin{gathered}
w_{i}=0.5\left(w_{i t}+w_{i t-1}\right) \\
d \ln \left(Q_{i}\right)=\ln \left(Q_{i t}\right)-\ln \left(Q_{i t-1}\right) \\
d \ln \left(P_{i}\right)=\ln \left(P_{i t}\right)-\ln \left(P_{i t-1}\right) \\
d \ln (Y)=\ln \left(Y_{t}\right)-\ln \left(Y_{t-1}\right)
\end{gathered}
$$

\footnotetext{
30 Troublingly, the only evidence cited in favour of the hypothesis of additivity is Selvanathan (1988).

31 The Rotterdam model has in the past frequently been used to test for the assumption of additivity e.g. Barten (1969) and Deaton (1974). And although the evidence obviously depends on the commodity classification and the time period under scrutiny the assumption of additivity is not generally found to be acceptable.

32 There is a very dated literature on estimating the value of $\eta$ or, as it was referred to at the time, the "Frisch parameter". A report on these efforts can be found in Brown and Deaton (1972) who report consensus estimates of -2 for this parameter. There is also a literature investigating whether the Frisch parameter is indeed constant or increases in absolute terms with income. For a discussion of attempts to test the "Frisch conjecture" see Taylor and Johnson (1987).
} 
Table 4 Non-linear least squares estimates of the Rotterdam system

\begin{tabular}{lll}
\hline Variable & $\begin{array}{l}\text { Model 1 } \\
\text { Coefficient } \\
\text { (T-statistic) }\end{array}$ & $\begin{array}{l}\text { Model 2 } \\
\text { Coefficient } \\
\text { (T-statistic) }\end{array}$ \\
\hline Constant & -0.000346 & -0.0000379 \\
& $(-0.77)$ & $(-1.30)$ \\
$\mathrm{d} \ln \mathrm{R}_{\mathrm{t}}$ & 0.0578 & 0.0581 \\
$\mathrm{~d} \mathrm{P}_{\mathrm{Ft}}$ & $(5.53)$ & $(5.93)$ \\
$\mathrm{d} \ln \mathrm{P}_{\mathrm{Nt}}$ & -0.0156 & \\
$\eta$ & $(-1.64)$ & \\
$\eta$ & 0.0151 & \\
$\mathrm{R}^{2}$ & $(1.59)$ & -3.57 \\
No. obs. & & $(1.63)$ \\
Log likelihood & 239.32 & 0.473 \\
\hline
\end{tabular}

Additivity involves imposing the following constraints on the substitution matrix:

$$
c_{i i}=\frac{1}{\eta} b_{i}\left(1-b_{i}\right)
$$

and

$$
c_{i j}=-\frac{1}{\eta} b_{i} b_{j}
$$

Consistent with previous research we analyse UK food and non-food commodity expenditures. Annual data are available from the ONS from 1964 to 2010. All variables are taken in per capita terms and prices are indexed such that the year $2006=100$. We calculate the price of the non-food commodity by assuming that the logarithm of the implied price index for all household expenditure $P$ is equal to the share weighted sum of the logarithm of $P_{F}$ and the logarithm of $P_{N}$ where these represent the price of the food and the non-food commodities respectively. ${ }^{33}$

The results from the econometric analysis are displayed in Table 4. Model 1 does not impose additivity. The estimate of the income elasticity of demand for food is 0.393 with an average budget share for food of 0.147 . The uncompensated own price elasticity is -0.164 whilst the compensated own price elasticity of demand is -0.106 . Turning to Model 2 , the restrictions associated with additivity are imposed and, surprisingly perhaps, these are accepted even at the $10 \%$ level of significance as shown by a Likelihood Ratio test $\left(\chi^{2}[1]=0.0105\right)$. The estimate for $\eta$ of -3.57 is however, disappointingly imprecise having a standard error of 2.188. For reasons of precision, the Frisch approach appears not to be a useful methodology at least in the UK context.

33 More specifically the analysis uses the data series ADIP, ABZV, ABQJ, ABQI and EBAQ. 
Table 5 Estimates of the coefficient of relative risk aversion for the UK using insurance data

\begin{tabular}{ll}
\hline Variable & Coefficient (T-statistic) \\
\hline $\mathrm{W}$ & 0.00595 \\
& $(23.56)$ \\
$\mathrm{W} \times \lambda$ & -0.00272 \\
& $(-6.69)$ \\
$\mathrm{R}^{2}$ & 0.9961 \\
F-statistic & $\mathrm{F}(2,8)=1269.61$ \\
\hline
\end{tabular}

\section{Measuring the Coefficient of Relative Risk Aversion Using Insurance Data}

There are several ways of estimating $\eta$ in the context of risk without resorting to experimental approaches. In this context however $\eta$ is usually referred to as the coefficient of relative risk aversion. These methodologies were recently reviewed by Outreville (2014). One approach is to consider investors' demand for risky assets e.g. Friend and Blume (1975). Here however, we investigate the opportunity to obtain an estimate of $\eta$ in its guise as the coefficient of relative risk aversion using data on the demand for insurance and wealth based upon the work of Szpiro (1986a). The attractions of this approach are its simplicity and the ubiquity of insurance.

Szpiro (1986a) demonstrates that the following relationship holds:

$$
I=W-\frac{\lambda}{a(W)},
$$

where I is the amount of insurance, $\mathrm{W}$ is wealth, $\lambda$ is insurance loading defined as (premiums - claims)/claims and $\mathrm{a}(\mathrm{W})$ is absolute risk aversion. Denoting the coefficient of relative risk aversion by $\eta(\mathrm{W})$ yields the relationship: $a(W)=\eta(W) / W$. Substituting this expression gives:

$$
I=W-\frac{\lambda W}{\eta}
$$

under the assumption of a constant coefficient of relative risk aversion (independent of wealth). Given that the amount of insurance $I$ is not observable, data on claims Q can be used on the assumption that the probability of loss q is constant since: $I=Q / q$. Making this substitution gives:

$$
Q=q W-\frac{q}{\eta} \lambda W
$$

It is expected that $\mathrm{q}$ is positive since it represents the probability of a claim whereas the coefficient on $\lambda \mathrm{W}$ is expected to be negative since the quantity of insurance declines with insurance loading. Thus $\eta$ is expected to be positive. ${ }^{34}$

In order to produce estimates of the coefficient of relative risk aversion for the United States as well as test whether or not it is constant Szpiro uses time series aggregate data on total wealth comprising the wealth of households, non-profit organisations, the Government

\footnotetext{
34 Note that Szpiro (1986a) suggests that the demand for insurance can be determined by multiplying through using either data on premiums or data on claims. That is to say that he assumes that either the rate of premiums is constant or that the rate of claims is constant. In later work however Szpiro (1986b) and Szpiro and Outreville (1988) present estimates based exclusively on the assumption that the claims rate is constant.
} 
and the net foreign balance. The insurance data he uses relates to property and liability insurance. With these data Szpiro determines that the coefficient of relative risk aversion is constant with respect to wealth and takes a value between 1 and 2 .

In order to estimate the coefficient of relative risk aversion for the United Kingdom using this technique we combine data on wealth from the ONS with data on non-health non-life insurance premiums and claims for domestic risks from the European insurance industry database. $^{35}$

The regression displayed in Table 5 is estimated using OLS. Like Szipro (1986b) and Szipro and Outreville (1988) our analysis assumes that the claims rate is constant. We argue that the premium rate cannot be constant if premiums are subject to taxes which vary over time as was indeed the case in the United Kingdom. The resulting estimate of the coefficient of relative risk aversion obtained by dividing the first coefficient in Table 5 by the (negative of) the second is $2.19 .{ }^{36}$ Using the delta method we test the hypothesis that the value of this parameter is equal to unity. The hypothesis can be rejected with a p-value of 0.001 . Once more it seems that the value of the $\eta$ might be in excess of unity.

\section{Subjective Well-Being}

Layard et al. (2008) present a method of estimating $\eta$ based on surveys of subjective wellbeing; a technique regarded as distinct from stated preference approaches. In such surveys individual respondents are invited to respond to questions such as:

All things considered how satisfied (or happy) are you on a 1-10 scale where 10 represents the maximum possible level of satisfaction and 1 the lowest level of satisfaction?

Life satisfaction is taken as being synonymous with utility and it is assumed that survey respondents are able accurately to map their utility onto an integer scale:

$$
S_{i}=h_{i}\left(U_{i}\right)
$$

where $\mathrm{S}_{\mathrm{i}}$ is the reported satisfaction of individual $i$ and $h_{i}$ describes a monotonic function used by individual $i$ to convert utility $U_{i}$ to reported $\mathrm{S}$. It is further necessary to assume all survey respondents use a common function $g$ to convert utility to reported S: $h_{i}=h \forall i$.

The functional relationship $h$ between $\mathrm{S}$ and $U$ determines the appropriate estimation technique. The least restrictive approach is to assume only an ordinal association between reported life satisfaction and utility. So if an individual reports an 8 one ought merely to assume that they are more satisfied than if they had reported a 7. This entails use of the ordered logit model. Analysing such data using ordinary least squares by contrast assumes a linear association between the utility of each respondent and their reported life satisfaction.

Layard et al. (2008) analyse six separate surveys variously containing questions on happiness and life satisfaction. The estimates for $\eta$ remain surprisingly consistent across datasets and are robust to different estimation techniques. Layard et al. (2008) nevertheless acknowledge that income reported in household surveys may contain measurement error (especially when respondents are required only to identify a range within which their income falls rather than the exact value). The estimate of $\eta$ for the British Household Panel survey is 1.32 with

\footnotetext{
35 Our estimate of wealth is series CGDA.

36 This estimate is similar to the estimate of 1.48 with a $95 \%$ confidence interval of $0.53-3.95$ obtained for the United Kingdom by Szpiro and Outreville (1988). Note however that their estimate is obtained using data not on wealth but on GNP and that it is based only on data from 1973 to 1979 .
} 
Table 6 Meta-analysis of estimates of $\eta$

\begin{tabular}{lll}
\hline Methodology & $\eta$ & Standard error \\
\hline Equal sacrifice (weighted) & 1.515 & 0.047 \\
Equal sacrifice (historical) & 1.573 & 0.481 \\
Euler equation & 1.584 & 0.205 \\
Additive preferences (rotterdam) & 3.566 & 2.188 \\
Demand for insurance & 2.187 & 0.242 \\
Subjective wellbeing & 1.320 & 0.168 \\
Fixed effects pooled estimate $(95 \% \mathrm{CI})$ & $1.528(1.443-1.613)$ & \\
Random effects pooled estimate $(95 \% \mathrm{CI})$ & $1.594(1.362-1.827)$ & \\
Parameter homogeneity & $\chi^{2}(5)=9.98(p=0.076)$ & \\
\hline
\end{tabular}

a confidence interval of 0.99-1.65 implying a standard error of 0.168 (these estimates are taken from the slightly less restrictive ordered logit model). Here anyway, we cannot quite reject the hypothesis that $\eta=1$.

\section{Meta-Analysis of $\eta$}

The preceding sections investigated five alternative methodologies for estimating $\eta$. We reviewed the evidence and in the case of four methodologies (the demand for insurance, the Frisch additive preferences approach, the Euler equation approach and the Equal Sacrifice approach) generated more up to date estimates along with their associated standard errors. The final methodology utilised data on Subjective Wellbeing. Here we merely identified a single estimate for Britain provided by Layard et al. (2008). These five (sets of) estimates and their associated standard errors are summarised in Table 6 . Here we use meta-analysis to combine these estimates to obtain a single 'best' estimate. Two different ways of combining these estimates are employed: a pooled fixed effects estimator and a random effects estimator. The difference between these two estimators is that whereas the former assumes that studies differ only because of random sampling the latter acknowledges probable differences between studies and attempts to estimate the mean of the distribution of all possible studies. Both estimators use information on the standard errors of the component estimates. ${ }^{37}$

The pooled fixed effects estimator for $\eta$ is 1.528 with a $95 \%$ confidence interval of $1.443-1.613$, whereas the pooled random effects estimator is 1.594 with a confidence interval of 1.362-1.827. Both pooled estimators clearly exclude the current Green Book estimate of unity (and they continue to do so even using 99\% confidence intervals). Furthermore the hypothesis of parameter homogeneity cannot be rejected. This latter finding is of interest because our estimates arise out of very different situations where others e.g. Atkinson et al. (2009) have suggested that the value of $\eta$ might differ depending on whether it reflects risk, the inter-temporal allocation of consumption or societal inequality aversion. If the weighted equal sacrifice study is excluded the fixed (random) effects pooled estimate of the remaining studies rises to 1.600 (1.671) with a 95\% confidence interval of 1.382-1.818 (1.273-2.069). If the historical equal sacrifice study is omitted then the fixed (random) effects pooled esti-

37 For further information on techniques of meta analysis see Hedges and Olkin (1985). For a recently published example of meta-analysis see Beltran et al. (2018). 
mate of the remaining studies is unchanged at 1.528 (1.603) with a 95\% confidence interval of 1.442-1.613 (1.345-1.861). If the additive preferences-based estimate is omitted the fixed (random) effects pooled estimate of the remaining studies is 1.527 (1.589) with a 95\% confidence interval of 1.442-1.612 (1.335-1.824). If the insurance-based estimate is omitted the fixed effects pooled estimate is 1.506 with a $95 \%$ confidence interval of $1.420-1.592$ (in this case the random effects estimator gives the same results as the fixed effects estimator).

Using a convenience sample the stated preference survey of Atkinson et al. (2009) by contrast reports median estimates of the coefficient of relative risk aversion of between 3 and 5 , estimates of inequality aversion of between 2 and 3 and a median estimate for aversion to inequality over time of $8.8 .^{38}$

\section{Implications for the SDR}

In this section we demonstrate the implications of our new estimate of $\eta$ for the SRTP (and hence the SDR) for the UK using the simple and the extended Ramsey rules. The Ramsey rule requires inputting an assumption about $g$ and the extended Ramsey rules require evidence on the historical variance and autocorrelation of $\mathrm{g}$. For illustrative purposes we estimate the model of persistent growth derived from the model discussed above in footnote 14. This model collapses to a simple $\mathrm{AR}(1)$ when it is assumed that $\varepsilon_{y t}$ and $\varepsilon_{x t}$ are identical. ${ }^{39}$ This is the same as assuming the following diffusion process:

$$
\ln \left(C_{t+1}\right)-\ln \left(C_{t}\right)=\mu+y_{t}
$$

where $\mathrm{C}$ is consumption and

$$
y_{t}=\varphi y_{t-1}+\varepsilon_{y t}
$$

and $\varepsilon_{\mathrm{yt}}$ is assumed to be distributed $\mathrm{N}\left(0, \sigma_{y \varepsilon}^{2}\right)$.

Concern about the long-run also raises questions about the appropriate period of data that should be used to determine the average growth rate. Once again we undertake a sensitivity analysis by distinguishing between Green Book growth assumptions and a longer run approach. The Green Book assumes that average growth is $2 \%$ based on an analysis of the period 1949-1998, yet consumption data are available for the 180 year period 1830-2009 in 2006 prices. $^{40}$

\footnotetext{
38 Examples of stated preference studies undertaken outside the UK attempting to measure respectively the coefficient of relative risk aversion, temporal inequality aversion and aversion to intra-generational inequality include respectively Pirttila and Uusitalo (2010), Andersson et al. (2016) and Barsky et al. (1997). They find estimates for $\eta$ of $>3,0.01-0.34$ and 8.7.

39 Note that this description of the growth of consumption is somewhat simpler than the one given in Gollier (2012) in which:

$$
\ln \left(C_{t+1}\right)-\ln \left(C_{t}\right)=\mu+\varphi Y_{t-1}+\varepsilon_{x t}+\varepsilon_{y t}
$$

and where $\varepsilon_{x t}$ and $\varepsilon_{y t}$ are mean zero normally distributed with variance $\sigma_{x \varepsilon}^{2}$ and $\sigma_{y \varepsilon}^{2}$. Bansal and Yaron (2004, p. 1485) describe the conditions for this state space model to collapse to a first order auto-regressive process $(\operatorname{AR}(1))$.

40 The series is constructed from historical data on consumption and inflation available from the Bank of England: www.bankofengland.co.uk/publications/.../threecenturiesofdata.xls (Last accessed 16/07/15) along with population data obtained from Jan Lahmeyer's "Populstat" website: www.populstat.info. Further details are contained in the Appendix in the notes to Table A2.
} 
Table 7 The SDR for the UK

\begin{tabular}{lccc}
\hline Data & $\begin{array}{l}\text { SDR } \\
\text { (certainty) }\end{array}$ & $\begin{array}{l}\text { SDR (with } \\
\text { prudence) }\end{array}$ & $\begin{array}{l}\text { SDR (Long } \\
\text { Horizon) }\end{array}$ \\
\hline Growth $=2 \% ; \sigma_{y \varepsilon}^{2}$ and $\phi$ measured between 1949 and 1998 \\
Unsmoothed & 4.50 & 4.46 & 4.39 \\
Smoothed (MA5) & 4.50 & 4.49 & 4.17 \\
Growth=1\%; $\sigma_{y \varepsilon}^{2}$ and $\phi$ measured between 1830 and 2009 \\
Unsmoothed & 3.0 & 2.92 & 2.85 \\
Smoothed (MA5) & 3.0 & 2.99 & 2.49 \\
\hline
\end{tabular}

Table A2 in the Appendix presents the results of the AR(1) estimation on per capita consumption growth in the UK using the long and the short time series of growth data. Models 1 and 3, both use the raw per capita consumption growth data. Models 2 and 4 use smoothed data: a 5 year moving average (MA5). The smoothing removes cyclical and short term fluctuation which may not be appropriate for discounting distant time horizons (Newell and Pizer 2003; Muller and Watson 2016). ${ }^{41}$

A comparison of Models 1 and 3 shows that average growth differs radically depending on which time period is analysed. Between 1949 and 1998, which is the period deemed relevant by the Green Book, per capita consumption has an annual growth rate of $2.3 \%$. However, between 1830 and 2009 annual growth has been a mere $1.1 \%$. This result is not affected by data smoothing. It is a moot point as to which period is more appropriate in the context of social discounting. Persistence, which is important for estimating the term structure of discount rates, differs depending on whether smoothed or unsmoothed data is used. This is to be expected and raises further empirical issues of consequence for estimating the term structure of discount rates.

In Table 7 we provide two alternative sets of estimates of the SDR. These include estimates for the SDR under certainty, with prudence and in the long-run [corresponding to Eqs. (1), (2) and (3) respectively]. The first employs all the parameter assumptions of HMT (i.e. $\delta=1.5$ and $g=2 \%$ ), except with $\eta$ now equal to 1.5 , in line with our empirical results. The parameters for prudence and the long-run $\left(\sigma_{y \varepsilon}^{2}\right.$ and $\left.\phi\right)$ are first estimated over the period 1949-1998, the period used by the Green Book to estimate average growth. We then estimate these parameters using data from the 180 year period of 1830-2009. In each case we report the results using unsmoothed and smoothed data.

Table 7 shows that, if one uses the value of $\eta$ derived from the meta-analysis and then combines it with the current assumptions concerning $\rho$ and HMT's preferred estimate of $g$ one obtains a value for the SDR more than $1 \%$ higher than that recommended in the Green Book. As elsewhere (e.g. Gollier 2012), the prudence effect is very small due to the relatively low variance of $\mathrm{g}$.

The main surprise however, is that explicitly accounting for the diffusion process of per capita consumption growth, and hence taking into account the uncertainty and persistence of growth, the resulting term structure of discount rates barely declines at all. This result is irrespective of whether the data is smoothed or not. The short horizon rates are at most only $0.5 \%$ higher than those appropriate for long-horizons, and are much higher than the $1 \%$ currently recommended for long-horizons in the Green Book. More important from the perspective of discounting the distant future, is the selection of the historical time series

41 The MA5 is chosen arbitrarily, but we smooth the data in line with previous work. We do this mainly for illustrative purposes. Smoothing introduces persistence to the series, but reduces variance, which have opposing effects on the term structure of discount rates in our application. 
for per capita consumption growth. This is a full percentage point lower when the period 1830-2009 is considered rather than the current Green Book choice of 1949-1998.

The message of this application is that our estimate of the elasticity of marginal utility leads to an increase in the SDR currently recommended in the Green Book, all else equal. Also, the current HM Treasury guidance that declining discount rates should be used for long-time horizons is seemingly not justified by our inspection of the time series properties of per capita consumption data. Care is needed though since we have not undertaken an exercise in model selection for the diffusion process. Also, an SRTP in excess of $4 \%$, looks high for a risk-free rate, even when one removes what the Treasury Green Book refers to as the 'catastrophic risk' element contained in their overall estimate of $\delta$, which is currently thought to be $1 \%$. Of course, the high theoretical value for the risk-free rate is partly a manifestation of the risk-free rate puzzle (Weil 1989). The risk-free rate puzzle is a potential problem for the SRTP approach to discounting if one thinks that the SRTP should be a predictor of the market risk-free rate. This is not the view in the Green Book however, whose approach to defining the SWF is normative, and not intended to have predictive power over interest rates. Nevertheless, the calibration does raise further issues about the validity of including catastrophic risk in the SDR, the treatment of systematic risk, and the potential for an SDR which adjusts to reflect current macroeconomic conditions. The theory of the term structure in Sect. 2 would recommend adjustments for lower or higher than expected growth, for instance. ${ }^{42}$ Our recommendation would be that these other elements of the SDR: growth, project risk and pure time preference, should be revised along with the elasticity of marginal utility to arrive at an empirically justifiable SDR.

\section{Conclusion}

In the nomenclature of social discounting this paper has taken a positive (revealed preference) approach to the estimation of the elasticity of marginal utility, rather than a normative approach (Arrow et al. 1996). Five separate empirical methods have been investigated, each of which uses revealed preference or subjective wellbeing data. The results suggest that the conceptual and empirical approach to estimating the elasticity of marginal utility in the UK is not materially important. Where Atkinson et al. (2009) referred to these different concepts (risk, inter-temporal substitution, and inequality aversion) as empirical "siblings not triplets", our results suggest a more accurate description might be "non-identical quintuplets". It is possible that the variety of estimates that Atkinson et al. (2009) arose due to framing effects in their hypothetical scenario, the absence of which is a benefit of revealed preference. Among other benefits of this result, it eliminates at least some of the potential for disagreement among experts on this matter, allowing a focus on other essential issues. That said, we see considerable benefit in attempting to replicate these results using data from other countries. We also see considerable benefits in incorporating stated preference evidence on $\eta$ obtained from representative surveys. Moreover, whether revealed preference data, based on private decisions, is always an appropriate source of information for the Social Discount Rate remains a matter of debate, particularly when it comes to intergenerational project appraisal.

The meta-analysis of the various estimates suggests that a value for $\eta$ of $1.5 \%$ is defensible for the UK, with confidence intervals which exclude unity, the value currently contained in the Green Book and preferred by the Stern Review (HMT 2003; Stern 2007). With no other changes the short run SDR for the UK becomes $4.5 \%$, up from the current value of $3.5 \%$.

42 See footnote 12. 
Analysis of long-run consumption growth further shows that simple persistence in growth justifies a term structure which hardly declines at all compared to the currently recommended $1 \%$ for horizons of 300 years. At most, the decline should go no lower than $2.5 \%$, when using estimates of growth (g) over the period 1830-2009. Taken on their own, these findings would have significant implications for long-lived man-made assets such as flood defences, biodiversity conservation, slow-growing natural resources such as forests and natural capital valuation more generally.

Yet the analysis gives rise to questions about the values of the other parameters if the SDR, since $4.5 \%$ is large for what is essentially a risk-free SRTP. This observation places focus on the other parameters of the SDR in the UK context, and also raises the issue of how catastrophic and project risk should be dealt with in a discounting context. The idea that there is a single discount rate for public policy analysis is questionable since projects have different risk profiles and recent work refutes the relevance of the risk free rate for public project appraisal (Baumstark and Gollier 2013). Ultimately, a unilateral change in the value of the elasticity of marginal utility should not happen without these other issues being dealt with in parallel. Other areas for consideration in this regard include judicious estimates of the expected level and diffusion of growth in the twenty-first century.

In conclusion, we have used several revealed preference methods to estimate the elasticity of marginal utility in this paper, each with its own interpretation. Ultimately, no estimate of $\eta$ is without criticism, yet assuming one wishes to take a positive approach the practical message of this paper is clear: in the case of UK the choice of method would make very little difference to the final policy recommendation of raising the value of $\eta$ from 1 to 1.5 as part of a wholesale review of the SRTP. Currently HM Treasury arguably does not reflect socially revealed preferences. This has implications for how policies and projects are appraised across government and how public resources are allocated over time.

Acknowledgements The authors would like to thank Ian Bateman, Simon Dietz, Moritz Drupp, Mark Freeman, Cameron Hepburn, Joseph Lowe, Frikk Nesje, Michael Spackman, the participants of the EnvEcon 2013 and EAERE 2014 conferences for useful comments and suggestions. We would also like to thank the participants at the June 2013 workshop entitled "Social Discounting in the UK" jointly organised by the LSE Department of Geography and Environment, the School of Business and Economics at Loughborough University and HM Treasury, and funded by the Grantham Research Institute on Climate Change and the Environment and Loughborough University. Finally we thank the two anonymous referees for their extremely helpful comments. All remaining errors remain our own.

Open Access This article is distributed under the terms of the Creative Commons Attribution 4.0 International License (http://creativecommons.org/licenses/by/4.0/), which permits unrestricted use, distribution, and reproduction in any medium, provided you give appropriate credit to the original author(s) and the source, provide a link to the Creative Commons license, and indicate if changes were made.

\section{Appendix: Results of the Time Series Analysis of UK Per Capita Consump- tion}

Table A1 re-estimates Eq. (6) using instrumental variables. The instrumental variables chosen are the lagged consumption growth rate, $\Delta \operatorname{Ln}\left(\mathrm{C}_{\mathrm{t}-1}\right)$, the lagged real rate of interest, $\mathrm{r}_{\mathrm{t}-1 \text {, }}$ and the lagged inflation rate, $\Delta \operatorname{Ln}\left(\mathrm{P}_{\mathrm{t}-1}\right)$. The coefficient on the real rate of interest is very similar to that obtained by the OLS regression and remains significant at the $1 \%$ level of confidence. The hypothesis of under-identification is easily rejected at the $1 \%$ level of significance whereas the Sargan test for instrument validity is not statistically significant even at the $10 \%$ level of significance. The Durbin-Wu-Hausman (DWH) test for endogeneity is 
likewise statistically insignificant at the $10 \%$ level of confidence. Tests of heteroscedasticity and autocorrelated errors are statistically insignificant at the 5\% level of significance whilst a test for functional form is statistically insignificant at the $10 \%$ level. In light of the tests for the Sargan statistic and the DWH test statistic we take the estimates from the OLS regression (see Table A1 for test results and Table 3 for the OLS results).

\section{How Additive Preferences Facilitate the Measurement of $\eta$}

Assume the existence of an explicitly additive direct utility function:

$$
U=U_{1}\left(Q_{1}\right)+U_{2}\left(Q_{2}\right)+\cdots+U_{n}\left(Q_{n}\right)
$$

Maximising this expression subject to a budget constraint yields:

$$
\frac{\partial U\left(Q_{i}\right)}{\partial Q_{i}}=\lambda P_{i}
$$

This is then differentiated first with respect to income and then with respect to $P_{j}$ and $P_{i}$ yielding respectively:

$$
\begin{gathered}
\frac{\partial^{2} U\left(Q_{i}\right)}{\partial Q_{i}^{2}} \frac{\partial Q_{i}}{\partial Y}=\frac{\partial \lambda}{\partial Y} P_{i} \\
\frac{\partial^{2} U\left(Q_{i}\right)}{\partial Q_{i}^{2}} \frac{\partial Q_{i}}{\partial P_{j}}=\frac{\partial \lambda}{\partial P_{j}} P_{i} \\
\frac{\partial^{2} U\left(Q_{i}\right)}{\partial Q_{i}^{2}} \frac{\partial Q_{i}}{\partial P_{i}}=\lambda+\frac{\partial \lambda}{\partial P_{i}} P_{i}
\end{gathered}
$$

Next, define the following elasticities:

$$
\begin{aligned}
\eta & =\frac{\partial \lambda}{\partial Y} \frac{Y}{\lambda} \\
\theta_{i} & =\frac{\partial \lambda}{\partial P_{i}} \frac{P_{i}}{\lambda}
\end{aligned}
$$

Rewriting the above equations using these elasticities yields:

$$
\begin{gathered}
\frac{\partial^{2} U\left(Q_{i}\right)}{\partial Q_{i}^{2}} \frac{\partial Q_{i}}{\partial Y} \frac{Y}{\lambda}=\eta P_{i} \\
\frac{\partial^{2} U\left(Q_{i}\right)}{\partial Q_{i}^{2}} \frac{\partial Q_{i}}{\partial Y} \frac{P_{j}}{\lambda}=\theta_{j} P_{i} \\
\frac{\partial^{2} U\left(Q_{i}\right)}{\partial Q_{i}^{2}} \frac{\partial Q_{i}}{\partial P_{i}} \frac{P_{i}}{\lambda}=P_{i}+\theta_{i} P_{i}
\end{gathered}
$$

This demonstrates the following holds:

$$
\eta e_{i j}=\kappa_{i} \theta_{j}+\mu_{i j} \kappa_{i}
$$

where $\mu_{\mathrm{ij}}$ is the Kronecker delta. Multiplying both sides by $w_{\mathrm{i}}$ yields:

$$
\eta w_{i} e_{i j}=w_{i} \kappa_{i} \theta_{j}+\mu_{i j} w_{i} \kappa_{i}
$$

Summing over $i$ and applying the Cournot aggregation:

$$
\sum_{i} w_{i} e_{i j}+w_{j}=0
$$


And adding up:

$$
\sum_{i} w_{i} \kappa_{i}=1
$$

Yields the following solution for $\theta_{\mathrm{i}}$ :

$$
\theta_{i}=-w_{i}\left(\eta+\kappa_{i}\right)
$$

Inserting this expression yields

$$
\eta e_{i j}=-\kappa_{i} w_{j}\left(\eta+\kappa_{j}\right)+\mu_{i j} \kappa_{i}
$$

Rearranging this expression yields:

$$
\begin{gathered}
e_{i i}=\varphi \kappa_{i}-\kappa_{i} w_{i}\left(1+\varphi \kappa_{i}\right) \\
e_{i j}=-\kappa_{i} w_{i}\left(1+\varphi \kappa_{i}\right)
\end{gathered}
$$

Finally, using the Slutsky equation:

$$
e_{i i}=\varepsilon_{i i}-\kappa_{i} w_{i}
$$

\begin{tabular}{|c|c|c|}
\hline \multirow{18}{*}{$\begin{array}{l}\text { Table A1 Instrumental variable } \\
\text { estimates of the Euler equation }\end{array}$} & \multirow{2}{*}{ Dependent variable $\Delta \operatorname{Ln}\left(C_{t}\right)$} & \multirow{2}{*}{ Model 3} \\
\hline & & \\
\hline & \multirow[t]{2}{*}{ Constant } & 0.043 \\
\hline & & $(15.77)$ \\
\hline & \multirow[t]{2}{*}{$\mathrm{r}_{\mathrm{t}}$} & 0.593 \\
\hline & & $(5.01)$ \\
\hline & \multirow[t]{2}{*}{ DUMQ1 } & -0.133 \\
\hline & & $(-23.83)$ \\
\hline & \multirow[t]{2}{*}{ DUMQ2 } & -0.008 \\
\hline & & $(-2.43)$ \\
\hline & \multirow[t]{2}{*}{ DUMQ3 } & -0.024 \\
\hline & & $(-5.58)$ \\
\hline & $\mathrm{R}^{2}$ (uncentred) & 0.9475 \\
\hline & F-statistic & $\mathrm{F}(4,139)=606.06^{* * *}$ \\
\hline & Under-identification & $\chi^{2}(3)=47.471^{* * *}$ \\
\hline & Sargan & $\chi^{2}(2)=3.691$ \\
\hline & DWH & $\chi^{2}(1)=0.22561$ \\
\hline & Pagan-Hall & $\chi^{2}(6)=11.833^{*}$ \\
\hline \multirow{2}{*}{$\begin{array}{l}\text { Note that } * * *, * * \text { and } * \text { imply } \\
\text { significance at the } 1,5 \text { and } 10 \%\end{array}$} & Cumby-Huizinga & $\chi^{2}(1)=3.4726693^{*}$ \\
\hline & Pesaran-Taylor & $\chi^{2}(1)=2.11$ \\
\hline
\end{tabular}

The first of these equations is most often shown as:

$$
\eta=\frac{\kappa_{i}\left(1-w_{i} \kappa_{i}\right)}{\varepsilon_{i i}}
$$

Table A1 Instrumental variable estimates of the Euler equation

\section{Model 3}


Table A2 AR(1) estimates of UK per capita consumption growth Sources: The data on consumption are taken from the UK Treasury Spreadsheet entitled "three centuries of growth data" which is available here: www.ban kofengland.co.uk/publications/.../threecenturiesofdata.xls. Aggregate consumption is converted to per capita consumption using the UK population data described below. The long-term consumption data are pieced together from different sources. For the period 1830-1920 the data is taken from Mitchell (1988), Chapter XVI, Table 6 pages 837 to 841. Data for the period 1921-1948 come from Sefton and Weale (1995) Table A.3. The remaining period (1948-2009) are the ONS series code NPSP. The population data used to obtain per capita consumption are also pieced together from different sources. From 1830 to 1972 we used data sourced from: http://www.populstat.info/Europe/unkingdc.htm (last accessed 17/07/15). In particular, from 1801 to 1947: AG, MI; 1948-1978: DY; 1979-1993: CE. Until 1922 only figures of Great Britain (England, Wales and Scotland); from 1922 onwards Northern Ireland is included. From 1973 onwards we use the Annual Population Survey (APS), which is described on the Office for National Statistics website as 'the Labour Force Survey (LFS) plus various sample boosts'. Population is enumerated at mid-year estimates from annual census (from 1961 to 2008) and population projections thereafter. Further information can be found on the National Statistics website www.ons.gov.uk, under population

\begin{tabular}{|c|c|c|c|c|}
\hline \multirow{2}{*}{$\begin{array}{l}\text { Dependent variable } \\
\ln \left(C_{t+1}\right)-\ln \left(C_{t}\right)\end{array}$} & \multicolumn{2}{|l|}{ 1949-1998 } & \multicolumn{2}{|l|}{ 1830-2009 } \\
\hline & $\begin{array}{l}\text { Model } 1 \\
\text { (unsmoothed) } \\
\text { Coefficient } \\
\text { (T-statistic) }\end{array}$ & $\begin{array}{l}\text { Model } 2 \\
\text { (smoothed) } \\
\text { Coefficient } \\
\text { (T-statistic) }\end{array}$ & $\begin{array}{l}\text { Model } 3 \\
\text { (unsmoothed) } \\
\text { Coefficient } \\
\text { (T-statistic) }\end{array}$ & $\begin{array}{l}\text { Model } 4 \\
\text { (smoothed) } \\
\text { Coefficient } \\
\text { (T-statistic) }\end{array}$ \\
\hline \multirow[t]{2}{*}{$\mu$} & 2.32 & 2.26 & 1.13 & 1.03 \\
\hline & $(5.36)$ & $(3.74)$ & $(4.16)$ & $(2.34)$ \\
\hline \multirow[t]{2}{*}{$\phi$} & 0.38 & 0.86 & 0.25 & 0.87 \\
\hline & $(3.02)$ & $(9.78)$ & $(2.83)$ & (16.28) \\
\hline \multirow[t]{2}{*}{$\sigma_{\varepsilon}^{2}$} & 3.61 & 0.57 & 7.45 & 0.76 \\
\hline & (10.27) & (10.62) & $(9.03)$ & (10.02) \\
\hline $\log \mathrm{L}$ & 103.2 & 43.6 & 433.5 & 206.7 \\
\hline Wald test & 9.1 & 95.7 & 8.0 & 265.0 \\
\hline$p$ value & 0.00 & 0.00 & 0.00 & 0.00 \\
\hline No. obs. & 50 & 50 & 179 & 179 \\
\hline
\end{tabular}

Standard errors are robust

\section{References}

Adam S, Loutzenhiser G (2007) Integrating income tax and national insurance: an interim report. Institute for Fiscal Studies Working Paper W07/21

ADB (2007) Theory and practice in the choice of social discount rate for cost-benefit analysis: a survey. Economics Working Papers. ERD Working Paper No. 94

Andersson O, Holm H, Tyran J, Wengström E (2016) Risk aversion relates to cognitive ability: preferences or noise? J Eur Econ Assoc 14:1129-1154

Arrow KJ (1999) 'Discounting, Gaming and Morality'. Ch 6 in 'Discounting and Intergenerational Equity'. In: Portney P, Weyant J (1999), Resources for the future, Washington. http://www-siepr.stanford.edu/w orkp/swp97004.pdf

Arrow K, Cline W, Mäler K-G, Munasinghe M, Squitieri R, Stiglitz J (1996) Intertemporal equity, discounting, and economic efficiency. In: Bruce HLJP, Haites E (eds) Climate change 1996: economic and social dimensions of climate change, contribution of working group III to the second assessment report of the intergovernmental panel on climate change. Cambridge University Press, Cambridge

Arrow K, Cropper M, Gollier C, Groom B, Heal G, Newell R, Nordhaus W, Pindyck R, Pizer W, Portney P, Sterner T, Tol RSJ, Weitzman M (2013a) Determining benefits and costs for future generations. Science 341(6144):349-350 
Arrow K, Cropper M, Gollier C, Groom B, Heal G, Newell R, Nordhaus W, Pindyck R, Pizer W, Portney P, Sterner T, Tol RSJ, Weitzman M (2013b) How should benefits and costs be discounted in an intergenerational context? The views of an expert panel: the views of an expert panel. Resources for the future discussion paper, pp 12-53

Atkinson G, Dietz S, Helgeson J, Hepburn C, Sælen H (2009) Siblings, not triplets: social preferences for risk, inequality and time in discounting climate change. Economics Discussion Papers, No 2009-14, Kiel Institute for the World Economy. http://www.economics-ejournal.org/economics/discussionpapers /2009-14

Attanasio O, Browning M (1995) Consumption over the life cycle and over the business cycle. Am Econ Rev 85(5):1118-1137

Attanasio O, Weber G (1989) Intertemporal substitution. Risk Aversion Euler Equ Consum Econ J 99:59-73

Attanasio O, Weber G (1993) Consumption growth, the interest rate and aggregation. Rev Econ Stud 60:631-649

Banks J, Blundell R, Lewbel A (1997) Quadratic engel curves and consumer demand. Rev Econ Stat LXXIX(4):527-539

Barsky R, Juster F, Kimball M, Shapiro M (1997) Preference parameters and behavioral heterogeneity: an experimental approach in the health and retirement study. Q J Econ 112:729-758

Barten A (1969) Maximum likelihood estimation of a complete set of demand equations. Eur Econ Rev 1:7-73

Baumstark L, Gollier C (2013) The relevance and the limits of the Arrow-Lind Theorem. Toulouse University, Mimeo. http://idei.fr/sites/default/files/medias/doc/by/gollier/Arrow-Gollier.pdf

Beltran A, Maddison DJ, Elliott RJ (2018) Is flood risk capitalised into property values? Ecol Econ 146:668-685

Berloffa G (1997) Temporary and permanent changes in consumption growth. Econ J 107:345-358

Blundell R, Pashardes P, Weber G (1993) What do we learn about consumer demand patterns from micro data? Am Econ Rev 83(3):570-597

Blundell R, Browning M, Meghir M (1994) Consumer demand and the life-cycle allocation of household expenditures. Rev Econ Stud 61:57-80

Brown A, Deaton A (1972) Surveys in applied economics: models of consumer behaviour. Econ J 82(328):1145-1236

Burgess S, Fernandez-Corugedo E, Groth C, Harrison R, Monti F, Theodoridis K, Waldron M (2013) The Bank of England's forecasting platform: COMPASS, MAPS, EASE and the suite of models. Bank of England No. 471

Campbell JY, Mankiw NG (1991) The response of consumption to income. Eur Econ Rev 35:723-767

Clements K, Gao G (2015) The rotterdam model half a century on. Discussion Paper 14.34, University of Western Australia

Cowell FA, Gardiner K (1999) Welfare weights STICERD. London School of Economics, London

Dasgupta P (2008) Discounting climate change. J Risk Uncertain 37:141-169

Deaton A (1974) The analysis of consumer demand in the United Kingdom, 1900-1970. Econometrica 42(2):341-367

Deaton A, Muellbauer J (1980) Economics and consumer behaviour. Cambridge University Press, Cambridge

Drupp M, Freeman MC, Groom B and Nesje F (2018) Discounting Disentangled. Forthcom Am. Econ. J: Policy. (Working paper version: Grantham Research Institute on Climate Change and the Environment Working Paper No. 172)

Epstein LG, Zin S (1989) Substitution, risk aversion and the temporal behaviour of consumption and asset returns: a theoretical framework. Econometrica 57(4):937-969

Evans DJ (2004a) A social discount rate for France. Appl Econ Lett 11:803-808

Evans DJ (2004b) The elevated status of the elasticity of marginal utility. Appl Econ Lett 11:443-447

Evans DJ (2005) The elasticity of marginal utility of consumption: estimates for 20 OECD Countries. Fisc Stud 26(2):197-224

Evans DJ (2008) The marginal social valuation of income for the UK. J Econ Stud 35(1):26-43

Evans DJ, Sezer H (2002) A time preference measure of the social discount Rate for the UK. Appl Econ $34: 1925-1934$

Evans DJ, Sezer H (2005) Social discount rates for member countries of the European Union. J Econ Stud 32(1):47-59

Evans D, Kula E, Sezer H (2005) Regional welfare weights for the UK: England, Scotland, Wales and Northern Ireland. Reg Stud 39(7):923-937

Feldstein M (1964) Opportunity cost calculations in cost-benefit analysis. Public Finance XIX:117-139

Fenichel EP, Abbott JK, Bayham J, Boone W, Haacker EM, Pfeiffer L (2016) Measuring the value of groundwater and other forms of natural capital. PNAS 113(9):2382-2387

Frederickson S, Loewenstein G, O’Donoghue T (2002) Time discounting and time preference: a critical review. J Econ Lit XL:351-401 
Friend I, Blume M (1975) The demand for risky assets. Am Econ Rev 66:900-922

Frisch R (1959) a complete scheme for computing all direct and indirect demand elasticities in a model with many sectors. Econometrica 27(2):177-196

Gollier C (2006) An evaluation of Stern's report on the economics of climate change. IDEI Working Paper, no. 464

Gollier C (2012) Pricing the Planet's future: the economics of discounting in an uncertain world. Princeton Press, Princeton

Gollier C (2017) Ethical valuation and the good society. Columbia University Press, Cambridge

Groom B, Hepburn C (2017) Reflections_-looking back at social discounting policy: the influence of papers, presentations, political preconditions, and personalities. Rev Environ Econ Policy 11(2):336-356

Hansen L, Singleton K (1982) Generalized instrumental variables estimation of nonlinear rational expectations models. Econometrica 50(5):1269-1286

Havranek T (2015) Measuring intertemporal substitution: the importance of method choices and selective reporting. J Eur Econ Assoc 13(6):1180-1204

Havranek T, Horvath R, Irsova Z, Rusnak M (2014) Cross country heterogeneity in intertemporal substitution. J Int Econ 96(1):100-118

Hedges LV, Olkin I (1985) Statistical methods for meta-analysis. The Academic Press, Cambridge

HMT (2003) Guidelines on cost benefit analysis. Her Majesty's Treasury, UK. www.hm-treasury.gov.uk/dat a_greenbook_index.htm

IAWG (2010) Appendix 15a: social cost of carbon for regulatory impact analysis under executive order 12866. US Interagency Working Group on the Social Cost of Carbon of the United States of America

Kaplan G, Moll B, Violante GL (2016) Monetary policy according to HANK. NBER Working Paper No. 21897

Kolstad C, Urama K, Broome J, Bruvoll A, Carino Olvera M, Fullerton D, Gollier C, Hanemann WM, Hassan R, Jotzo F, Khan MR, Meyer L, Mundaca L (2014) Social, economic and ethical concepts and methods. In: Edenhofer O, Pichs-Madruga R, Sokona Y, Farahani E, Kadner S, Seyboth K, Adler A, Baum I, Brunner S, Eickemeier P, Kriemann B, Savolainen J, Schlomer S, von Stechow C, Zwickel T, Minx JC (eds) Climate change 2014: mitigation of climate change. Contribution of working group III to the fifth assessment report of the intergovernmental panel on climate change. Cambridge University Press, Cambridge

Koopmans TC (1960) Stationary ordinal utility and impatience. Econometrica 28:287-309

Kugler P (1988) Intertemporal substitution taste shocks and cointegration. Econ Lett 26:235-239

Layard R, Mayraz G, Nickell S (2008) The marginal utility of income. J Public Econ 92:1846-1857

Lebegue D (2005) Revision du taux d.actualisation des investissem- net publics. Rapport du groupe de experts, Commisariat Generale de Plan. http://catalogue.polytechnique.fr/site.php?id=324\&.leid=2389

Lind R (1982) A primer on the major issues relating to the discount rate for evaluating national energy options. In: Lind R (ed) Discounting for time and risk in energy policy, resources for the future. Routledge, Washington

Lynch F, Weingarten N (2010) UKDA Study No. 6358-EuroPTax. Who pays for the state? The evolution of personal taxation in postwar Europe, 1958-2007. http://www.esds.ac.uk/findingData/snDescription.asp $? \mathrm{sn}=6358$

Mill J (1848) Principles of political economy. John W. Parker, London

Mitchell BR (1988) British historical statistics. Cambridge University Press, Cambridge

MNOF (2012) Cost benefit analysis. Official Norwegian Reports NOU 2012: 16. Ministry of Finance, Norway

Muller UK, Watson MW (2016) Low frequency economics. https://www.princeton.edu/ umueller/ULFE.pdf

NAS (2017) Valuing climate damages: updating estimation of the social cost of carbon dioxide. National Academies Press, Washington, DC

NCC (2017) Improving natural capital: an assessment of progress. Fourth report to the economic affairs committee, natural capital committee. https:/www.gov.uk/government/uploads/system/uploads/attach ment_data/file/585429/ncc-annual-report-2017.pdf

Newell RG, Pizer WA (2003) Discounting the distant future: how much do uncertain rates increase valuations? J Environ Econ Manag 46:52-71

Nordhaus WD (2007) A review of the stern review on the economics of climate change. J Econ Lit XLV:686-702

Nordhaus WD (2014) Estimates of the social cost of carbon: concepts and results from the DICE-2013R model and alternative approaches. J Assoc Environ Resour Econ 1:273-312. https://doi.org/10.1086/676035

Outreville J (2014) Risk aversion, risk behaviour and demand for insurance: a survey. J Insur Issues 37:158-186

Patterson KD, Pesaran B (1992) The intertemporal elasticity of substitution of consumption in the United States and United Kingdom. Rev Econ Stat. XXIV(4):573-584

Pearce D, Ulph D (1995) A social discount rate for the United Kingdom. CSERGE Working Paper GEC 95-01 
Pirttila J, Uusitalo R (2010) A leaky bucket in the real world: estimating inequality aversion using survey data. Economica 77:60-76

Quinet E (2013) L'évaluation socio-économique en période de transition, Rapport du groupe de travail présidé par Émile Quinet, Commissariat général à la stratégie et à la prospective Tome I, Rapport final, Juin

Ramsey FP (1928) A mathematical theory of saving. Econ J 38:543-559

Reed H, Dixon M (2005) National insurance: does it have a future? Public Policy Res 12(2):102-110

Robertson D, Scott A (1993) The estimation of single equation rational expectations models: an application to UK consumption. Oxford Bull Econ Stat 55(2):237-244

Sefton J, Weale M (1995) Reconciliation of national income and expenditure: balanced estimates of national income for the United Kingdom, 1920-1990. Cambridge University Press, Cambridge

Selvanathan S (1988) A system-wide analysis of international consumption patterns. PhD Thesis, University of Western Australia, Perth

Spackman M (2004) Time discounting and the cost of capital in government. Fiscal Stud 25(4):467-518

Stern N (1977) Welfare weights and the elasticity of the marginal valuation of income. In: Artis M, Nobay AR (eds) Studies in modern economic analysis. Basil Blackwell, Oxford

Stern N (2007) The economics of climate change: the stern review. Cambridge University Press, Cambridge Szpiro G (1986a) Measuring relative risk aversion: an alternative approach. Rev Econ Stat 68:156-159

Szpiro G (1986b) Relative risk aversion around the world. Econ Lett 20:19-21

Szpiro G, Outreville J (1988) Relative risk aversion around the world: further results. Stud Banking Finance 6:127-128

Taylor G, Johnson L (1987) The frisch conjecture and demand systems. Q J Bus Econ 26(1):63-77

USEPA (2010) Guidelines for preparing economic analyses. United States Environmental Protection Agency, Washington DC

Van Dalen H (1995) Intertemporal substitution in war and peace: evidence from the United Kingdom, 1830-1990. J Macroecon 17(3):447-469

Weil P (1989) The equity premium puzzle and the risk free rate puzzle. J Monet Econ 24:401-421

Weitzman ML (2001) Gamma discounting. Am Econ Rev 91(260):271

Yogo M (2004) Estimating the elasticity of intertemporal substitution when instruments are weak. Rev Econ Stat 86(3):797-810 